ISSN: 0213-2087 e-ISSN: 2444-7080

DOI: https://doi.org/10.14201/shhcont382020265293

\title{
CUANDO AÚN NO ERA «EL JEFE». UN ENSAYO BIOGRÁFICO DEL PRIMER JOSÉ MARÍA GIL-ROBLES (1898-1931)
}

\author{
When he was not yet "The Boss". \\ A biographical essay of the first \\ José María Gil-Robles (1898-1931)
}

\author{
Carlos M. RODRÍGUEZ LÓPEZ-BREA \\ Universidad Carlos III de Madrid \\ cmrodrig@hum.uc3m.es
}

Recibido: 06/07/2020 Revisado: 15/07/2020 Aceptado: 24/07/2020

RESUMEN: José María Gil-Robles y Quiñones (1898-1980) tenía un sólido pasado como activista católico antes de 1931. De familia tradicionalista (fue hijo del catedrático Enrique Gil y Robles), supo evolucionar y durante los años veinte participó a las órdenes de Ángel Herrera Oria en la consolidación del movimiento católico español, siendo la selecta Asociación Católica Nacional de Propagandistas la que tuvo una mayor relevancia en su formación intelectual. Militante del Partido Social Popular en 1922, colaboró con la dictadura de Primo de Rivera durante largos años, rompiendo con la misma solo en 1929. Se implicó en la defensa de la monarquía en el difícil contexto de 1930-1931, al tiempo que junto a otros propagandistas profundizaba en el magisterio de León XIII y diseñaba fórmulas de acción política para un posible futuro republicano. Gil-Robles demostró gran flexibilidad para adaptarse a los diferentes contextos políticos, lo que hizo que Herrera y el nuncio Tedeschini lo auparan como líder de la derecha católica en 1931.

Palabras clave: Gil-Robles; Catolicismo político; Propagandismo; Movimiento católico español.

ABSTRACT: José María Gil-Robles y Quiñones (1898-1980) had a strong past as a Catholic activist before 1931. Born in a traditionalist family (he was the son of Professor 
Enrique Gil y Robles), he evolved and during the 20's he participated in the consolidation of the Spanish Catholic movement under the orders of Angel Herrera Oria, being the select National Catholic Association of Propagandists the group that had the greatest relevance in his intellectual formation. Member of the Partido Social Popular in 1922, he collaborated with the dictatorship of Primo de Rivera for long years, breaking with it only in 1929. He was involved in the defense of the monarchy in the difficult context of 1930-1931, while along with other propagandists he delved into the magisterium of León XIII and designed formulas of political action for a possible republican future. Gil-Robles showed great flexibility to adapt to different political contexts, which made Herrera and the nuncio Tedeschini helped him up as leader of the Catholic right in 1931.

Key words: Gil-Robles; Political Catholicism; Propagandism; Spanish Catholic Movement.

\section{INTRODUCCIÓN}

Decir que la historia biográfica sigue siendo una rama controvertida en el campo de las ciencias sociales no es sino constatar una evidencia. Más que el interés de la comunidad científica, lo que ha sostenido en pie a la biografía ha sido el interés del público, aunque las más vendidas y consumidas son obra de periodistas, literatos y publicistas, agradecidos de ocupar el cetro abandonado por los historiadores ${ }^{1}$.

Los prejuicios no han desaparecido, por mucho que la actual historia biográfica haya conseguido revitalizar el género asignándole un espacio propio entre las grandes estructuras y los hábitos cotidianos, entre lo complejo y lo trivial, entre lo repetitivo y lo irrepetible, entre el sujeto y el colectivo. En atinadas palabras de Isabel Burdiel, «un individuo no puede explicar completamente un grupo, una comunidad o una institución, y viceversa, un grupo, una comunidad o una institución no puede explicar completamente a un individuo [...] Hay una interdependencia recíproca, pero ésta no es ni lineal ni univalente»².

La biografía hecha por historiadores no podrá ser tal si no enfatiza su utilidad social. Anna Caballé ha subrayado, en este sentido, que la biografía es una eficaz herramienta contra el olvido ${ }^{3}$ que, entre otras cosas, redimensiona trayectorias tenidas por ejemplares, rescata personajes injustamente denigrados o matiza verdades establecidas. Tareas en

1. Jacques Maurice ya advertía en 2011 sobre el relativo subdesarrollo de la historia biográfica en España, en comparación sobre todo con el mundo anglosajón (cfr. MAURICE, Jacques: «Présentation», Biographies politiques, Cahiers de Civilization Espagnole Contemporaine. De 1808 au temps présent, 8, 2011, en línea.

2. Burdiel, Isabel: «Historia política y biografía: más allá de las fronteras», Ayer, 93, 2014, pp. 47-83 y particularmente pp. 68-69; LORIGA, Sabina: "La escritura biográfica y la escritura en los siglos XIX y XX». En: BuRDIEL, Isabel; Foster, Roy (eds.): La historia biográfica en Europa. Nuevas perspectivas. Zaragoza: Institución "Fernando el Católico», 2015, pp. 15-45.

3. CABallé, Anna: "La biografía en España: primeras propuestas para la construcción de un canon". En: Burdiel, Isabel; Foster, Roy (eds.), op. cit., pp. 116-117. 
DEL PRIMER JOSÉ MARÍA GIL-ROBLES (1898-1931)

absoluto nuevas, pero ineludibles si la biografía pretende sobrevivir a modas y críticas, armada con el rigor de los científicos sociales y la buena escritura de los humanistas.

En este trabajo se asume esta perspectiva, con el objetivo de ofrecer nuevas claves de la vida de un personaje de larga trayectoria, José María Gil-Robles y Quiñones, en su etapa más desconocida, anterior a su jefatura de la derecha española en 1931. No es que no se sepa nada del tramo vital de la presente investigación, pero nunca se había presentado como un objeto de estudio en sí mismo. Complica sobremanera la ausencia de fuentes de archivo, ya que el variopinto Fondo Beltrán de Heredia — custodiado en el Archivo General de la Universidad de Navarra y que es lo más parecido a un archivo personal de Gil-Robles - no cubre el período previo a 1931. Se ha cubierto esa carencia con una búsqueda sistemática en fuentes hemerográficas, nacionales y regionales, aportando algunas publicaciones poco conocidas o raramente estudiadas para el caso de Gil-Robles, como el semanario estudiantil El Eco Escolar o el Boletín de la Asociación Católica Nacional de Propagandistas, congregación donde el joven salmantino creció intelectualmente, dictando lecciones y participando en debates que constituyen una pieza imprescindible para desentrañar la evolución del personaje.

Aunque la vida de Gil-Robles esté marcada por su cercanía a los propagandistas y a Ángel Herrera en particular, nos proponemos demostrar que la evolución vital e ideológica del futuro líder de la CEDA se fraguó en tres momentos: su formación tradicionalista en Salamanca, su afiliación al propagandismo, en plena crisis del sistema parlamentario, y su colaboración en la dictadura de Primo de Rivera, etapa esta última en la que Gil-Robles fue madurando una identidad propia, en lo político y en lo personal. En línea con algunos de los últimos estudios que se han hecho sobre el asunto, se relativizará la existencia de un bloque compacto entre propagandismo, catolicismo social y las distintas emanaciones políticas de los católicos. Hubo indudables reciprocidades y complicidades entre todos ellos, pero no sumisiones ni dependencias ciegas 4 .

Otro lugar común que rodea a Gil-Robles es el de su presunta volatilidad ideológica y estratégica, que supuestamente desconcertó a sus seguidores. Aunque esa imagen de veleta fue probablemente una mixtificación de la extrema derecha para desacreditar a un vecino político, se tratará de desentrañar si en sus años de juventud Gil-Robles dio muestras de ser un camaleón político, o si, por el contrario, definió unos principios inmutables, aunque subordinase la consecución de estos a las circunstancias cambiantes de la política española. Las crisis políticas de 1922-1923 y de 1929-1931 serán el mejor laboratorio para analizarlo.

4. WatAnABE, Chiaki: Confesionalidad católica y militancia política: la Asociación Católica Nacional de Propagandistas y la Juventud Católica Española (1923-1936). Madrid: UNED Ediciones, 2003, pp. 74-76 y 396-437; Villa García, Roberto: La República en las urnas. El despertar de la democracia en España. Madrid: Marcial Pons, 2011, pp. 275 y ss. 


\section{LOS AÑOS SALMANTINOS}

Aunque poco conocido por la opinión pública, José María Gil-Robles no era un neófito cuando en 1931 se puso al frente de Alianza Nacional, la heterogénea alianza de las derechas no republicanas de las Cortes Constituyentes ${ }^{5}$. Hijo del catedrático Enrique Gil y Robles, había nacido en Salamanca el 27 de noviembre de 1898, en una vetusta casa a caballo entre la Universidad y la Catedral Nueva. Salamanca era entonces una ciudad provinciana con unas veinticinco mil almas, cuya centenaria Universidad reunía a tres mil estudiantes repartidos en cuatro facultades (Derecho, Filosofía, Medicina y Ciencias) ${ }^{6}$.

Profesor de Derecho Político, el padre era uno de los intelectuales más destacados del tradicionalismo español, perfil muy distinto al de la madre, Petra Quiñones Armesto, una mujer de piedad arraigada y modales sencillos. Adversario declarado del liberalismo, Enrique Gil y Robles se las había tenido con el obispo salmantino, don Tomás Cámara, al que tildaba de modernista ${ }^{7}$, y más aún con Unamuno en lo relativo a la autonomía universitaria, que Gil y Robles defendía y que don Miguel fustigaba, el primero por su enemistad al centralismo liberal ${ }^{8}$, el segundo por estimar que esa misma autonomía

5. Entre las biografías de Gil-Robles, Arrabal, Juan: José María Gil-Robles. Su vida, su actuación, sus ideas. Ávila: Senén Martín Díaz, 1935 (1ed 1933); Boissel, Antony. S.J.: Un Jefe: Gil-Robles. San Sebastián: Librería Internacional, 1934; CoRTÉs CAVANILlas, Julián: Gil-Robles, ¿Monárquico? Misterios de una política. Madrid: Librería San Martín, 1935; Fernández Arias, Adelardo (El Duende de la Colegiata): Gil-Robles, jla esperanza de España! Madrid: Unión Poligráfica, 1936; "José María Gil-Robles». Vidas. Biografías anecdóticas, 3, 1936; GutiérReZ-RAvé, José: Gil-Robles, caudillo frustrado. Madrid: Prensa Española, 1967. En tiempos más recientes, Ardid Pellón, Miguel A. y Castro-Villacañas, Javier: José María Gil-Robles. Barcelona: Ediciones B, 2004; Rojas Quintana, Alfonso: José María Gil-Robles. Historia de un injusto fracaso. Madrid: Síntesis, 2010; GonzÁlez Calleja, Eduardo, "José María Gil-Robles. ¿Quién soy yo?». En: Quiroga Fernández de Soto, Alejandro; Del ArCo Blanco, Miguel Ángel (eds.): Soldados de Dios y Apóstoles de la Patria. Las derechas españolas en la Europa de entreguerras. Granada: Comares, 2010, pp. 304-329; ÁlvarEz TARDío, Manuel: Gil-Robles, un conservador en la República. Madrid: FAES-Gota, 2016; Rodríguez López-Brea, Carlos y González Calleja, Eduardo: «Un derrotado en La Victoria: José María Gil-Robles y la Guerra Civil española (1936-1939)», Revista Universitaria de Historia Militar, 13, 2018, pp. 104-133 [en línea: http://ruhm.es/index.php/RUHM/article/view/421/352].

6. Rabaté, Jean-Claude: 1900 en Salamanca. Guerra y paz en la Salamanca del joven Unamuno. Salamanca: Ediciones de la Universidad de Salamanca, 1997, pp. 107, 147-149, 183, 252, 287.

7. Tomás Jenaro de Cámara y Castro, obispo de Salamanca entre 1885 y 1904, fue un prelado muy popular entre la población local por sus obras de caridad. Defendió con ardor a María Cristina de Habsburgo y a su hijo Alfonso XIII, a los que sirvió como senador y miembro del consejo de Su Majestad. Notable intelectual, el "padre Cámara" tuvo sonados encontronazos con Unamuno — simpatizante socialista esos años - y también con el tradicionalista Gil y Robles (cfr. EsTeBAn DE VEGA, Mariano: «El padre Cámara y la Iglesia española de finales del siglo XIX y comienzos del siglo XX", Salamanca: Revista de Estudios, 33-34, 1994, pp. 109-122).

8. GIL y RoBles, Enrique: La libertad universitaria. Salamanca:1882. 
DEL PRIMER JOSÉ MARÍA GIL-ROBLES (1898-1931)

abonaba la endogamia y el caciquismo. Ambos simbolizaban una Salamanca dividida entre una mayoría integrista y una minoría racionalista, de raigambre krausista?

El niño José María Gil y Quiñones creció en este ambiente de libros, disputas y rezos, solo alterado en 1903 cuando su padre, reconciliado con la rama carlista tras una breve militancia en el integrismo de Nocedal, fue elegido en 1903 diputado a Cortes por Pamplona, lo que obligó a la familia a trasladarse a Madrid. El periodo madrileño apenas duró dos años, el tiempo que don Enrique tardó en cansarse de la vida parlamentaria («aquella atmósfera de convencionalismos y mentiras») y reincorporarse a su cátedra salmantina ${ }^{10}$.

Vuelto a Salamanca, José María completó sus estudios primarios y su bachillerato en los Salesianos. Pese al tradicionalismo paterno, las escuelas de Dom Bosco no practicaban una enseñanza convencional, sino modernas pedagogías no represivas en las que los alumnos hacían prácticas de laboratorio o realizaban actividades deportivas casi a diario. Era un colegio de pago, adecuado para una familia acomodada como la de los Gil y Quiñones, aunque ofrecía facilidades para la matriculación de niños pobres, lo que, a decir del jovencito, le permitió conocer muy pronto un tipo de cristianismo «infinitamente más social que de clase».

Todo ese horizonte de confort se vino abajo con la inesperada muerte de Enrique Gil y Robles en junio de 1908, en plena lealtad a su rey Carlos VII de Borbón. El fallecimiento de un profesor tan respetado conmovió a la intelectualidad española, incluso a la republicana; se atribuye a Giner de los Ríos el haber gestionado el cambio de apellido de los dos hijos del finado para que perviviera en ellos tan ilustre referencia; es así como José María Gil y Quiñones pasó a figurar en el registro como José María Gil-Robles y Quiñones.

La falta de padre acentuó la tendencia del niño al retraimiento. Con su madre las relaciones eran más distantes y además le gustaba pasar las horas recluido en la vasta biblioteca familiar, donde leyó los cuentos de Calleja, las novelas de Julio Verne y Salgari o los Episodios Nacionales de Pérez Galdós. Alumno aventajado en la escuela, concluyó el bachillerato antes de lo previsto y pudo inscribirse como estudiante en la Universidad de Salamanca en 1914, a punto de cumplir dieciséis años ${ }^{11}$.

9. González Cuevas, Pedro Carlos: El pensamiento politico de la derecha española en el siglo XX: de la crisis de la Restauración al Estado de partidos (1898-2000). Madrid: Tecnos, 2005, pp. 42-45; PESET, Mariano: "Unamuno, rector de Salamanca», Bulletin Hispanique, 104-2, 2002. pp. 883-904 [en línea: http:// www.persee.fr/doc/hispa_0007-4640_2002_num_104_2_5138]; RABATÉ, Jean-Claude: «Estudiantes católicos contra estudiantes liberales en la Salamanca de 1900", Salamanca: Revista de Estudios, 38, 1996, pp. 169-190; Esteban de VEGA, Mariano: "Católicos contra liberales: notas sobre el ambiente ideológico salmantino en la Restauración", Studia Historica. Historia Contemporánea, 4, 1986, pp.51-69.

10. "Don Enrique Gil-Robles", El Correo Español. Diario Tradicionalista, 27-VI-1908.

11. Gil-Robles, José María: La fe a través de mi vida. Bilbao: Desclée de Brouwer, 1975, pp. 19-31. 
La institución que acogía al adolescente Gil-Robles no había cambiado nada desde la muerte de su padre. La facultad más numerosa seguía siendo de largo la de Derecho, que fue en la que José María se matriculó. Aunque durante su primer año quiso simultanear los estudios de Leyes con los de Filosofía y Letras, abandonó la idea por falta de tiempo y prefirió concentrase en la carrera con mayores expectativas profesionales, la de Derecho ${ }^{12}$.

Jovencito apocado y beato, no le resultó sencillo adaptarse al ambiente estudiantil, tan libertino a sus ojos. Apenas pisaba el Novelty, el nuevo y distinguido café que abarrotaban profesores y alumnos, cuyo ambiente elegante contrastaba con el de las viejas tascas castellanas. Tímido para hablar con las chicas, no tuvo otros amoríos que los platónicos, de fugaces miradas. En los años finales de la carrera logró superar algunos complejos y potenció una fina ironía que ya le acompañó toda su vida. En horarios vespertinos se le podía ver en el cine o en el teatro y con más frecuencia en los billares. Con todo, su preferencia era por los toros, más aún si el diestro era su idolatrado Joselito; eficiente organizador de becerradas universitarias, en el ruedo se dio a conocer con el sobrenombre taurino de Pepe Gil-Robles ${ }^{13}$.

Muy buen estudiante, Gil-Robles sacó su carrera con brillantez, con quince sobresalientes — todos con premio de Honor-y un notable ${ }^{14}$. Su etapa universitaria apenas conoció otro contratiempo que la algarada estudiantil de noviembre de 1917, originada por el rumor de que el Ministerio quería recuperar las reválidas y que se saldó con pedradas y ocupación de clases por los manifestantes, en su mayoría alumnos de la Escuela Normal. Aunque los de Derecho se desmarcaron de las protestas, la reacción desmesurada de las fuerzas del orden se saldó con una breve detención de Gil-Robles y de varios de sus compañeros de curso, confundidos con un grupo de estudiantes violentos ${ }^{15}$.

Indignados, Gil-Robles y sus amigos se sirvieron de los dos periódicos editados entonces en Salamanca, El Salmantino y El Adelanto, para negar toda implicación en los hechos. Lo ocurrido fue además un acicate para que Gil-Robles diera forma a una vieja idea, la de fundar y dirigir una publicación estudiantil que diera a conocer las inquietudes de los universitarios por cauces pacíficos. El rotativo, bautizado como $E l$

12. Pérez Delgado, Tomás: «Vivir de la fama. Dos historias de la Universidad de Salamanca en el siglo XX». En: Rodríguez San Pedro Bezares, Luis Enrique; Polo Rodríguez, José Luis (coords.), La Universidad Contemporánea. Salamanca, Ediciones de la Universidad de Salamanca, 2008, pp. 147-150; RodRíGUEz-SAN Pedro Bezares, Luis Enrique: «La Universidad de Salamanca: evolución y declive de un modelo clásico", Studia Historica. Historia Moderna, 9, 1991, pp. 19-21.

13. "Una aclaración”, El Salmantino, 22-III-1918; "La becerrada de ayer», El Salmantino, 8-IV-1918.

14. Ribagorda, Álvaro: "Gil-Robles y Quiñones, José María (1898-1980)». En: PetrT, Carlos (ed.): Derecho ex cathedra. 1847-1936. Diccionario de catedráticos españoles, Madrid, Dykinson, 2019, pp. 198-199.

15. "Algarada juvenil», El Salmantino, 23-XI-1917; "La algarada estudiantil de ayer», El Adelanto. Diario de Salamanca, 24-XI-1917. 
DEL PRIMER JOSÉ MARÍA GIL-ROBLES (1898-1931)

Eco Escolar, se editó semanalmente entre enero de 1918 y marzo de 1919, con obligadas interrupciones en tiempo de exámenes y en verano. Tal fue la implicación de Gil-Robles en esta empresa que, según escribiría, «la redacción funcionaba de hecho en mi casa» ${ }^{16}$.

El Eco Escolar, aunque apolítico, era un semanario defensor del corporativismo universitario, que Gil-Robles — fiel a su padre — creía violado por sucesivas directrices ministeriales. Predominaba el ideario conservador, con tintes tradicionalistas. Sus redactores pretendían ser propositivos, porque querían hacer saber a la opinión salmantina que «los estudiantes no solo sirven para provocar huelgas y algaradas y perturbar el orden». No faltaban secciones satíricas y mordaces - las mejores-, que sus autores firmaban con seudónimos para protegerse de la posible represalia del profesor señalado; creemos que Gil-Robles firmó con al menos con dos apodos, Curioso Kind y El Bedel, este segundo posiblemente compartido con otro brillante redactor, el también estudiante de Derecho Antonio Niño Astudillo. El Bedel rubricaba la sección más celebrada, "Figuras del claustro", una semblanza paródica de un profesor, juzgado con benignidad o severidad en función de su interés por las clases y su trato con los alumnos.

En la pluma de Gil-Robles se adivina un tono socarrón y chispeante, lleno de dobles sentidos. Fue Unamuno el que salió peor parado en las páginas de El Eco Escolar, por veleta y por no representar nada, salvo "sabiduría palabrera». "No sirve ni para lo heroico ni para lo trágico; su papel está en el sainete», sentenció el joven Gil-Robles, sin duda condicionado por la prolongada enemistad que el intelectual bilbaíno había mantenido con su padre ${ }^{17}$. El frío en las aulas, los prolongados cierres de la biblioteca, la indolencia de los bedeles, la carencia de laboratorios dignos o el absentismo de los docentes fueron las quejas más frecuentes en El Eco Escolar. Las clases, anodinas y excesivamente teóricas, cimentaban licenciados en Derecho que jamás se habían enfrentado a un caso práctico en sus años universitarios.

Puede ser que Salamanca no le formara como abogado, pero sí como periodista y opinador, aferrado a una pluma para ganar la batalla de la opinión. Fue también en su etapa universitaria cuando Gil-Robles inició en la Congregación de San Luis Gonzaga su fructífera militancia en el apostolado católico. Dependientes de la Compañía de Jesús, los conocidos como "Luises» agrupaban a jóvenes varones de familias universitarias, juntando rezos, charlas magistrales de vida cristiana, ocio y deporte. Los jesuitas también despertaron en Gil-Robles el gusto por la música alemana, Beethoven y Brahms en particular, aunque su interés por todo lo alemán probablemente provenga de su ferviente germanofilia durante la Gran Guerra ${ }^{18}$.

16. El Eco Escolar. Semanario Estudiantil, 1918-1919 [En línea: https://prensahistorica.mcu.es/es/ consulta/registro.do?id=7144].

17. "Figuras del claustro", El Eco Escolar, 25, 28-XII-1918.

18. Gil-Robles, José María: op. cit., pp. 40-42; Ogara, Florentino S.J.: "Lo que es un centro o círculo de "Luises", La Estrella del Mar. Revista quincenal ilustrada. Órgano de las Congregaciones Marianas de Lengua Española, 14, 8-IX-1920. 
Fue en «los Luises» donde Gil-Robles se estrenó como orador. Los jesuitas obligaban a sus jóvenes adheridos a impartir conferencias ante auditorios selectos, que le planteaban objeciones de las que el orador debía salir triunfante. La primera conferencia de Gil-Robles de la que tenemos noticia fue en noviembre de 1917, con el título "La colonización española en América», precisamente en "los Luises». En ella planteó una cerrada defensa de la acción de España en el Nuevo Continente y sostuvo que quienes la criticaban no merecían siquiera el nombre de españoles. En sesiones posteriores trató cuestiones de gran actualidad, como los progresos del moderno regionalismo catalán, a su juicio criminal y disgregador, o la situación en la Rusia de los sóviets, que interpretó como resultado del liberalismo individualista nacido de la Ilustración ${ }^{19}$. Demostraba con ello ser un joven curioso e interesado por los problemas del mundo, que diseccionaba desde una perspectiva profundamente conservadora.

Pero quien verdaderamente causó sensación en el joven estudiante fue Ángel Herrera Oria, que acudió a Salamanca a finales de 1918 a impartir una conferencia titulada «Regionalismo y autonomía universitaria». En su discurso, el ilustre apologeta católico hizo una encendida defensa de la autonomía de Castilla, como respuesta, dijo, a las demandas separatistas catalanas, que amenazaban con destruir España. Al terminar el acto, Herrera departió con los chicos de El Eco Escolar y los animó a trabajar por "nuestra madre Castilla», idea que el director de El Debate recuperó en 1923 con el nombre de uniones patrióticas. No mucho después las vidas de Herrera y de GilRobles volverían a cruzarse ${ }^{20}$.

\section{CATÓlico político}

Los días de Gil-Robles en Salamanca culminaron con el Premio Extraordinario de Licenciatura, que le fue concedido el 23 de octubre de 1919. Tras un largo verano de reflexión, decidió trasladarse a Madrid para iniciar su doctorado en Derecho Político, la misma especialidad que su padre. Eligió director de tesis a un viejo conocido de su progenitor, el catedrático José Gascón y Marín, un influyente diputado del Partido Conservador que llegaría a ser ministro de Instrucción Pública en el gabinete Aznar de 1931. Con José María se instalaron en la capital de España su madre y su hermana, convencidas de que su obligación como mujeres cristianas era ayudar al varón en su carrera profesional.

Gil-Robles redactó su tesis con envidiable rapidez, sirviéndose de la rica colección de libros heredada de su padre y de las novedades bibliográficas que encontraba

19. "En los Luises. La conferencia de ayer", El Adelanto. Diario de Salamanca, 19-XI-1917; "En los Luises. La conferencia del señor Gil-Robles», El Salmantino, 15-I-1919; "En los Luises. Conferencia de D. José María Gil-Robles", El Adelanto. Diario de Salamanca, 14-XI-1919.

20. "Conferencia del señor Herrera», El Eco Escolar, 25, 28-XII-1918. 
DEL PRIMER JOSÉ MARÍA GIL-ROBLES (1898-1931)

en las bibliotecas del Senado y del Ateneo. La defendió en septiembre de 1920, con calificación de sobresaliente ${ }^{21}$. El sobrio título del trabajo, de apenas cien páginas, $E l$ Derecho y el Estado y el Estado de Derecho (Rechtsstaat), escondía un alegato contra el imparable ascenso del moderno Estado, que el autor interpretaba como una amenaza a las tradiciones patrias. Con Balmes y su padre de referentes, Gil-Robles sostenía que la democracia representativa, tan en boga en 1918, era efecto de la colonización política del protestantismo sobre el sur de Europa, que en el caso español había arrasado con los "gobiernos moderados y templados" de raigambre secular. Se entiende así su simpatía por el constitucionalismo inglés (un mal menor), que por su carácter evolutivo había sido capaz de mantener en vigor las instituciones tradicionales, incluida la aristocracia, a la que Gil-Robles elogiaba por sus esencias cristianas y caballerescas. La desgracia de España no había sido la nobleza, ni tan siquiera el feudalismo, que al menos supo "reducir a vida social el individualismo", sino el centralismo liberal, constructor de una «unidad puramente coactiva» que ignoraba la «unidad moral de la nación cristiana». Frente al yugo liberal, el autor defendía una amplia descentralización administrativa avalada con fórmulas corporativas. Interpretaba el Estado como un engranaje armonizador de regiones, municipios, universidades, colegios profesionales y otras colectividades arraigadas, como la nobleza y el clero, creado en consonancia con el Derecho Público cristiano ${ }^{22}$.

Poco después de la lectura de su tesis, publicó junto al historiador —y también congregante de «los Luises»— Luis García Rives, un ensayo sobre la idea de patria y de nación en Menéndez Pelayo, que obtuvo el premio de la Biblioteca Menéndez Pelayo de Santander. Gil-Robles asumía la noción emocional de patria del polígrafo cántabro — «no compatible con las obras didácticas»— que, en el caso de España, hundía sus raíces en el catolicismo, pues sin religión —-sostenía—, "ni la nación ni la patria pueden formarse ni subsistir». Junto al catolicismo, el ensayo vindicaba los legítimos fueros de las pequeñas patrias, expresión de un regionalismo sano compatible con el amor a la patria grande. En su mente, España era un agregado de instituciones y territorios autónomos, unidos por su amor al Rey y a la Religión ${ }^{23}$. Parece así probado que a la altura de 1921 Gil-Robles no había roto amarras con el tradicionalismo de su padre y que se mantenía fiel a dicha ideología.

21. Gil-Robles, José María: op. cit., pp. 54-55; Ribagorda, Álvaro: op. cit., p. 198.

22. GiL-Robles y QuiÑones, José María: El Derecho y el Estado y el Estado de Derecho (Rechtsstaat). Estudio de Derecho Político, presentado como tesis doctoral por José M. Gil-Robles y Quiñones. Salamanca: Editorial Salmantina, 1922, pp. 45-54 y 96; "El cristianismo y la aristocracia», Boletín de la ACNdP, 62, 5-XI1928; "La autonomía universitaria», El Eco Escolar, 19, 19-XI-1918

23. García Rives, Luis y Gil-Robles, José María: "La Patria y la región, según Menéndez y Pelayo", Revista de Archivos, Bibliotecas y Museos, 4-6 y 7-9, 1922, pp. 260-280 y pp. 453-474. Aunque los autores usaron los conceptos de patria y nación como sinónimos, mostraban algún reparo mayor hacia la palabra nación, para ellos con connotaciones más próximas al «cáncer racionalista». 
Ya doctor, Gil-Robles obtuvo una ayudantía en la cátedra de Derecho Político de Gascón y Marín, un regalo envenenado porque el pope conservador acababa de ser destinado a la Organización Internacional del Trabajo, en Ginebra, y el nuevo profesor tuvo que asumir la carga docente de su maestro, coincidiendo además con su llamada al servicio militar. Para su fortuna, la mili del joven doctor fue de lo más suave, destinado en el primer regimiento de ingenieros de ferrocarriles del Cuartel de la Montaña de Madrid, a tiro de piedra de su casa. Podía dormir en su domicilio y tampoco tuvo mayores dificultades para simultanear sus clases matutinas con la actividad en el cuartel por la tarde. La familia Gil-Robles abonó además las 2.000 pesetas exigidas a los soldados de cuota, lo que redujo su período de mili a solo cinco meses. Puestos a conseguir, convenció a los mandos militares para que no le raparan el pelo al cero, aduciendo que semejante facha provocaría la hilaridad de sus alumnos. A pesar de su ventajosa condición, el futuro ministro de Guerra vivió su servicio militar con gran desagrado. Poco amigo de recibir órdenes, solo se interesó por ascender a cabo y ello, en sus palabras, "para poder liberarme de las rudas y mecánicas tareas del soldado de segunda ${ }^{24}$.

Pero si algo marcó su vida al establecerse en Madrid fue el ingreso en la Asociación Católica Nacional de Jóvenes Propagandistas (ACNdP), formalizado en enero de 1920. Aunque siguió ligado a "los Luises", la muy elitista ACNdP, fundada por el padre Ayala y potenciada por Ángel Herrera, ofrecía un mejor cauce para sus inquietudes intelectuales y religiosas ${ }^{25}$. La actividad de los propagandistas se desarrollaba en selectos círculos con no más de 10 o 12 participantes, una fórmula similar a la de los actuales seminarios académicos; en sesiones maratonianas, precedía la disertación de uno o varios miembros del grupo sobre un tema previamente acordado, para continuar con un dinámico debate y concluir con una puesta en común de las ideas surgidas en la discusión, aunque Herrera solía reservarse el último turno. Las cuestiones a debate tenían un indisimulado componente político (fascismo, republicanismo, dictadura, regionalismo...), interpretados bajo el prisma de la doctrina de León XIII y del moderno catolicismo social de Bélgica, Italia o Alemania, sin ignorar a los más célebres tratadistas españoles, como Suárez o Balmes ${ }^{26}$.

El ingreso de Gil-Robles en la ACNdP no agradó inicialmente a su madre, convencida de que la de Herrera era una asociación modernista fatalmente influida por León

24. Gil-Robles, José María: op. cit., pp. 55-56.

25. En sus primeros años en Madrid, Gil-Robles alternó actividades en los Luises y en los propagandistas y aunque se inclinó por estos últimos como queda dicho, nunca se desvinculó de la Congregación de la Compañía de Jesús, participando en actos y conferencias y con colaboraciones esporádicas en sus publicaciones.

26. Montero, Feliciano: El Movimiento Católico en España, 1889-1936. Alcalá de Henares: Servicio de Publicaciones de la Universidad de Alcalá de Henares, 2017, pp. 158-162; Watanabe, Chiaki: op. cit., pp. $25-76$. 
DEL PRIMER JOSÉ MARÍA GIL-ROBLES (1898-1931)

XIII, un papa modernista para la familia carlista. Doña Petra acertó en parte, porque la ACNdP cambió en parte las ideas de su hijo, quien sin renunciar a principios como el corporativismo o el regionalismo - banderas del carlismo, pero también del maurismo o del catolicismo social-, se sintió cada vez más incómodo con el mundo tradicionalista, que comenzó a ver como dogmático y sectario, poco útil para la era de las masas ${ }^{27}$.

En los círculos propagandistas, Gil-Robles coincidió con otros jóvenes prometedores, como Santiago Fuentes Pila, Francisco de Luis, Fernando y Javier Martín-Sánchez Juliá, Marcelino Oreja, Alfredo López, Federico Salmón o José María Valiente, con algunos de los cuales fundó en 1920 la Confederación de Estudiantes Católicos, sección española de la Internacional de Estudiantes Pax Romana. Todos ellos viajaron con frecuencia por Europa y América y pudieron conocer de cerca los progresos del catolicismo de masas, en sus vertientes política, apostólica y sindical ${ }^{28}$. La Confederación reunía varias asociaciones provinciales de estudiantes católicos, que pese a los buenos propósitos de la ACNdP fueron surgiendo con extremada lentitud. Una de las primeras en crearse fue la de Salamanca, que Gil-Robles inauguró en febrero de 1922 ante un auditorio inesperadamente peleón. El orador hizo una encendida defensa del confesionalismo universitario y fustigó a los defensores del neutralismo religioso, falsos revolucionarios que portaban «el germen de la muerte». «O católicos o no católicos», concluyó. Para sorpresa de todos, le replicó un estudiante de Medicina, Rafael Cáceres, que para regocijo de algunos presentes aseguró que, como médico en ciernes, jamás había visto ese germen mortal en un microscopio. Descolocado, Gil-Robles no fue capaz de salir de su guion y contestó de mala manera, una actitud que no sería extraña en sus años de dirigente político, sobre todo cuando se veía acorralado por su interlocutor. Para evitar nuevos sobresaltos, en sus siguientes actos con jóvenes estudiantes españoles, la organización le procuró un auditorio más entregado y dócil29.

Entre viajes, clases y círculos, el inquieto Gil-Robles también opositó a la cátedra de Derecho Político Español Comparado con el Extranjero, que obtuvo en su segundo intento en mayo de 1922 aupado con un brillante ejercicio de constitucionalismo comparado en el que analizó las democracias surgidas en la Europa de 1918. Como la plaza era para la Universidad de La Laguna, en Canarias, el nuevo catedrático pidió una excedencia voluntaria, argumentando que no podía dejar solas en Madrid a su madre y a su hermana. Aparte de los motivos familiares, Gil-Robles tampoco mostró

27. Gil-Robles, José María: op. cit., pp. 69-70.

28. "Los estudiantes católicos», La Correspondencia de España, 23-II-1922; WatanaBe, Chiaki: op. cit., pp. $129-174$.

29. "La Asociación de Estudiantes Católicos. El discurso de Gil-Robles. Interesante debate», El Adelanto. Diario de Salamanca, 27-II-1922; "La Asociación Católica de Estudiantes», La Tribuna Escolar. Semanario Estudiantil, 4-III-1922, "Academia de Santo Tomás. Cuestiones escolares», El Adelanto. Diario de Salamanca, 6-III-1922. 
el menor entusiasmo por incorporarse a una universidad menor, filial entonces de la Universidad de Sevilla, donde solo había una sección de Derecho asociada a la casa madre hispalense, sin otros estudios que los preparatorios para un examen de ingreso en la ciudad andaluza. Poca cosa para un joven ambicioso como él ${ }^{30}$.

Pero lo que verdaderamente le retuvo en Madrid fue el consejo de sus dos mentores, Ayala y Herrera, que le animaron a centrarse en los trabajos de apostolado. Herrera también le ofreció integrarse en el consejo de redacción del diario católico El Debate, conocedor de la vocación periodística de su pupilo. Como redactor de plantilla, GilRobles escribió decenas de editoriales y artículos de opinión sobre diversos asuntos, aunque rarísima vez los firmó con su nombre. Por su fácil pluma, Herrera le confió más adelante la subdirección del diario, un cargo más honorífico que ejecutivo, porque el verdadero hombre fuerte de El Debate era, tras Herrera, el también propagandista Francisco de Luis, con quien Gil-Robles nunca mantuvo buena sintonía. La relación de amistad entre Ángel Herrera y Gil-Robles fue muy estrecha en aquel tiempo, aunque es sabido que la misma se enfrió notablemente durante la Segunda República, para romperse de hecho en 1936. Dolido por esa ruptura, Gil-Robles juzgaría después con gran dureza a su mentor, tildándole de frío y rígido, pero ese juicio no desmentía la cercanía que sintieron hasta al menos 1931, intimidad cimentada con paseos por el Guadarrama, viajes por el extranjero o confidencias por las calles de Madrid ${ }^{31}$.

Gil-Robles no quiso descuidar tampoco sus actividades profesionales como abogado. Tras pedir la excedencia de su cátedra, trabajó varios meses como pasante en un bufete madrileño, donde aprendió todo el Derecho Procesal que la Universidad no le había enseñado ${ }^{32}$. Después abrió bufete propio junto a su amigo José María Valiente, fomentando una clientela de propietarios agrarios, intereses católicos de provincias y también, por su defensa de la autonomía local, municipios en disputa contenciosa-administrativa contra el Estado, gracias a lo cual pudo vivir con holgura, como se verá más adelante.

Pero si Gil-Robles tuvo una verdadera pasión, esa fue la política. «Me atrae más que ninguna otra actividad de este mundo», confesó a un medio argentino en $1934^{33}$. Aunque de familia carlista, no se implicó en el tradicionalismo de modo activo; su primera militancia en política se remonta a finales de 1922, en el seno del Partido Social

30. Previamente Gil-Robles había opositado, sin éxito, a la cátedra de Derecho Político español Comparado con el Extranjero de la Universidad de Santiago de Compostela, siendo derrotado por Carlos Ruiz del Castillo, futuro militante del Partido Social Popular e impulsor del municipalismo en España, coincidiendo en ambas facetas con Gil-Robles (cfr. Guía Oficial de España. Madrid: Rivadeneyra, 1923, p. 728; «La Gaceta», La Época, 27-I-1923; "Nuevo catedrático, Don Carlos R. Del Castillo», El Debate, 30-VII-1921; "Índice de La Gaceta", La Escuela Moderna. Suplemento, 24-I-1923).

31. Gil-Robles, José María: op. cit., pp. 71-76.

32. Ibidem, pp. 81-82.

33. Salaverría, José María: "El caudillo de las derechas en España», Caras y Caretas (Buenos Aires), $13-I-1934$. 
DEL PRIMER JOSÉ MARÍA GIL-ROBLES (1898-1931)

Popular PSP), un nuevo grupo fundado por católicos de distinta procedencia - mauristas, católicos sociales, tradicionalistas moderados, independientes-, reunidos con el propósito de regenerar la monarquía española bajo las pautas del catolicismo social. Junto a Gil-Robles se afiliaron al PSP otros destacados propagandistas como Luis Lucia, Manuel Giménez Fernández, Miguel Herrero, Santiago Fuentes Pila, Marcelino Oreja, Federico Salmón o José Ibáñez Martín. Los estatutos de la ACNdP no impedían a sus miembros militar en un partido político, siempre que dicha afiliación no les impidiera conservar su libertad de acción y que el partido en cuestión fuera compatible con los principios católicos, lo que era el caso ${ }^{34}$.

El PSP, pese a su reducida militancia, nació como partido con vocación de masas y anticaciquil, hijo también de la oleada democratizadora de la Europa de posguerra. Algunas de sus propuestas resultaban audaces para la política española, entre otras cosas, la elección popular de los alcaldes, la progresividad fiscal, un mayor control parlamentario a los ministros, el impulso al regionalismo, la moralización de la vida pública o la representación proporcional en las Cortes; en sintonía con la doctrina de León XIII los populares también incidían en el «sentido social» de la propiedad, negando que la propiedad privada fuera un absoluto ${ }^{35}$.

En cualquier caso, los propagandistas afines al PSP tenían particular interés en definir su modelo de democracia como cristiana o integral, no parangonable con la liberal. La democracia de los cristianos, opinaba Gil-Robles, no era individualista ni partitocrática, sino corporativa, foral y pre-absolutista, con una concepción no monopolista de la soberanía y con una fuerte participación de los cuerpos intermedios, sobre todo regiones y municipios. Ángel Herrera declararía, hablando de la democracia liberal, que «es una de tantas ideas deslumbradoras, sin pizca de sentido real. Bien está el pueblo en el gobierno, pero moderadamente» ${ }^{36}$.

Gil-Robles acudió al congreso constituyente del PSP en Zaragoza, en diciembre de 1922, como corresponsal de El Debate. Impresionado por la calidad de las intervenciones, se sumó a ellas como un afiliado más y en ambiente de asamblea, se le encomendó participar en la redacción de una de las ponencias del congreso, la de "Régimen político y administrativo». Muy en su línea, Gil-Robles propugnó una definición netamente confesional del nuevo partido, pero el plenario suavizó la propuesta al aprobar un enunciado alternativo que abogaba por inspirarse en las doctrinas del

34. Sigue siendo referencias ineludibles, Alzaga VillaAmil, Óscar: La primera democracia cristiana en España. Barcelona: Ariel, 1973, en particular pp. 208-220; Tusell, Javier: Historia de la Democracia Cristiana en España (I). Madrid: Sarpe, 1986, pp. 102-118.

35. "Asamblea de política social», El Globo, 13-XII-1922; "Política social», El Debate, 16-XII-1922; "Se practicarán los principios del derecho público cristiano», El Debate, 17-XII-1922, "Una Asamblea. El Partido Social", El Globo, 18-XII-1922.

36. "El Debate, férvido, católico y batallador", Heraldo de Madrid, 2-IV-1928. 
catolicismo social y ajustarse a las enseñanzas de la Iglesia, subrayando al tiempo la plena independencia en la acción política del partido. Gil-Robles sí logró en cambio introducir una coletilla en los estatutos que refería «la subordinación de fines que existe entre las sociedades religiosa y civil»y, especialmente, la perentoria obligación de formar una alianza con todas las fuerzas católicas «cuando peligrasen principios fundamentales del orden religioso o social», mandato que contentó al ala más conservador del PSP, representada entre otros, por Gil-Robles ${ }^{37}$.

Lo dicho no permite definir al PSP como un partido aconfesional a la manera del Partito Popolare Italiano de Dom Sturzo, referente moral del sector más progresista de los populares españoles, con Ossorio y Gallardo al frente ${ }^{38}$. Muy lejos de Ossorio, Gil-Robles puso siempre en valor el carácter neta y genuinamente católico del partido y ante auditorios con presencia carlista mencionaba el sentido tradicional del grupo, con la intención de captar el mayor voto católico posible.

Aunque no entró en la ejecutiva del PSP, Gil-Robles se comprometió sin reservas con su partido, participando en conferencias y actos de propaganda. Formó parte de la comisión de régimen político del secretariado técnico, un puesto relativamente menor, aunque con fuerte peso en la conformación de ideas, que el propagandismo copó con nombres como Oreja, Herrero o Salmón, lo que sugiere una estrategia coordinada en la ACNdP para hacerse con el control ideológico del partido, con notable éxito, por cierto.

El Gil-Robles de 1923 se mostró particularmente combativo en la defensa de la representación parlamentaria proporcional, una de las banderas del PSP y cuestión de moda en media Europa. Lo curioso es que Gil-Robles adaptó su demanda de proporcionalidad a su ideario corporativo, al sostener que la representación proporcional favorecía la inserción en las Cortes de partidos pequeños de intereses y de agrupaciones ciudadanas no políticas, que él entendía como un paso previo para la futura -y deseable - implantación del corporativismo. Abogó igualmente por hacer obligatorio el voto secreto en cabina y por incluir en las papeletas un signo especial de cada partido, de modo que los analfabetos pudieran votar sin servirse de intermediarios. Sorprende que un declarado enemigo de la democracia liberal abogue por estas medidas, que aparte de lo dicho, deben interpretarse como una primera evidencia del pragmatismo que marcó la acción política de Gil-Robles en los años de la República39.

37. "Los mauristas de Goicoechea y los ex-mauristas de Vallellano", La Voz, 28-XII-1922; "La Asamblea acuerda el nombre de Partido Social Popular", El Debate, 19-XII-1922.

38. El debate no era nuevo en el catolicismo político de entreguerras. Incluso el presuntamente aconfesional Dom Sturzo tuvo que transigir con el ala "clerico-moderata» de su movimiento. El Zentrum en cambio se inclinó por el confesionalismo (cfr. Brezzi, Camillo: Il cattolicesimo politico in Italia nel'900. Milano: Teti Editore, 1979, pp. 43-45). Algún periódico habló de una declaración de «absoluta indiferencia” del PSP respecto a la autoridad eclesiástica, pero no fue realmente así (cfr. «Partido social popular», El Sol, 2-I-1923).

39. "La representación proporcional", $A B C, 8-\mathrm{II}-23$; "Conferencia sobre la representación proporcional", El Sol, 8-II-1923. Gil-Robles abjuró tiempo después de su cerrada defensa del proporcionalismo, achacándolo 
DEL PRIMER JOSÉ MARÍA GIL-ROBLES (1898-1931)

Para que no hubiera dudas de su verdadera opinión al respecto, Gil-Robles se refirió en un mitin en el Teatro de la Comedia de Madrid al «cadáver corrompido e insepulto de la falsa democracia liberal» y en otro acto celebrado en Leganés abogó por un gobierno fuerte "civil o militar, de la derecha o de la izquierda", al que prestaría su ayuda — recalcó- «aun cuando prescinda del texto de la ley» ${ }^{40}$. El descrédito del parlamento era generalizado entre las gentes del PSP, al punto que renunciaron a concurrir a las legislativas de abril de 1923, pero con un matiz sustancial que distanciaba a Gil-Robles de Ossorio y Gallardo: el salmantino no fustigaba la democracia liberal por tratarse de un régimen circunstancialmente maltrecho por el caciquismo y la corrupción - la tesis de Ossorio-, sino por su esencia individualista y partitocrática. Pese a su relativo distanciamiento del tradicionalismo, Gil-Robles aún mantenía en 1923 fuertes lazos con el pensamiento de su padre, algo común, por otra parte, entre las distintas culturas políticas de las derechas católicas, entre las que no dejó de haber conexiones e interrelaciones ${ }^{41}$.

\section{DiCTADURA: ESPERANZAS Y DESILUSIONES}

Gil-Robles vivió con ilusión el exitoso pronunciamiento del general Primo de Rivera, convencido de que se abría una oportunidad de gestar el régimen corporativo que preconizaba. En el seno del PSP se produjo una fuerte división ante el hecho militar, aunque fueron más los que asumieron la posición de los propagandistas, partidarios de colaborar con la Dictadura en tanto ésta «realice aspiraciones contenidas en el programa del PSP o cuando haga lo que convenga a España». El colaboracionismo, aconsejaba Ángel Herrera, habría de ser más intenso en aquellas materias que interesaban a los populares, como el régimen municipal y regional y el desarrollo de un programa social $^{42}$. Defensor de la colaboración, Gil-Robles asumió la jefatura de Vanguardia Social-Popular, nombre que se dio a las juventudes del PSP, con misiones específicas

a un error de juventud: en 1969 escribió que la experiencia ha demostrado que la representación proporcional ha favorecido la creación y la supervivencia de ambiciones personalistas, de partidos artificiales, de grupos vocalistas engendradores de Parlamentos ingobernables» (cfr. Gil-Robles, José María: Por un Estado de Derecho, Ariel, Barcelona, 1969, pp. 147-148).

40. "Importante mitin del Partido Popular», El Debate, 20-II-1923; "Mitin del PSP en Leganés", El Debate, $15-\mathrm{V}-1923$.

41. SALOMÓN ChÉLIZ, Pilar: «Entre el insurreccionalismo y el posibilismo: las culturas políticas del catolicismo español (1875-1936)». En: ForCadell, Carlos; SuÁrez CorTina, Manuel (eds.), La Restauración y la Republica (1874-1936). Historia de las culturas políticas en España y América Latina, vol. 3. Madrid-Zaragoza: Marcial Pons-PUZ, 2015, pp. 315-344, especialmente pp. 319-321.

42. «El PSP. Se produce una escisión y se retira el grupo disidente. Se nombra un Directorio Provisional", La Voz, 10-XII-1923; AlZaga VillaAmil, Óscar: op. cit., pp. 281-288. 
de propaganda, organización y estudio ${ }^{43}$. Aunque esta Vanguardia no sobrevivió a la disolución del PSP en 1924 —integrándose en la Unión Patriótica primorriverista—, esta implicación de los jóvenes en acciones callejeras y organizativas sirvió como modelo para la futura Juventud de Acción Popular (JAP) de la Segunda República, que tuvo en Gil-Robles su gran promotor ${ }^{44}$.

Los jóvenes propagandistas estaban ansiosos de asumir el mayor protagonismo político en el nuevo tiempo abierto en septiembre de 1923. Para Gil-Robles se inauguraba un período constituyente y una revolución social que pondría fin al caciquismo. Herrera, por su parte, aspiraba a convertir la ACNdP en una suerte de think tank al servicio del dictador, una de cuyas primeras propuestas fue crear un amplio movimiento ciudadano de raíces castellanas, conformado por hombres nuevos, ajenos al turnismo, unidos en defensa de la religión y del campo. Se usaron nombres como "movimiento regionalista castellano", "acción castellana» o «uniones patrióticas", grupos que, a medio plazo, debían confluir en un movimiento unitario y patriótico, edificado de abajo a arriba 45 .

Igualmente implicado en la forja de Unión Patriótica, Gil-Robles exacerbó los perfiles antiliberales de su discurso, en una línea que le acercaba a la derecha radical del momento. Llegó a dudar de la bondad de la fiscalización parlamentaria al Gobierno, que a su juicio podría desempeñar la prensa con mejor tino. Defensor ahora de los gobiernos fuertes, propugnaba por reducir las asambleas a órganos técnicos y deliberativos, sin partidos políticos, sustituidos por «agrupaciones apoyadas en fuertes masas de opinión", siguiendo el modelo de las uniones patrióticas y de los grupos de intereses $^{46}$. No resultó así, porque Primo de Rivera eligió una vía más obvia y fabricó su UP como un partido de poder, construido desde arriba por alcaldes y gobernadores civiles, auxiliados no pocas veces por los caciques de siempre. Las páginas del boletín de la ACNdP traslucen una primera decepción ya hacia 1925, aunque se hacían votos por la evolución del régimen hacia una «suavizada dictadura civil» con menor intervención

43. "Notas políticas. El Partido Social Popular», La Acción, 17-I-1924.

44. Lowe, Sid: Catholicism, War and the foundation of Francoism. The Juventud de Acción Popular in Spain, 1931-1939. Sussex: Sussex Academic Press, 2010.

45. Bullón de Mendoza ha mencionado las claves de este programa: mantenimiento del orden, autoridad, unidad de la Patria, moralización de costumbres, familia, lucha contra la blasfemia y la pornografía, abaratamiento de la vida, libertad de enseñanza, regionalismo, apoyo a la agricultura, industria y comercio, defensa de la propiedad, de la infancia, sanidad, reforma tributaria, reforma tributaria, reorganización del Ejército, etc. (cfr. Bullón de MendozA, Alfonso: José Calvo Sotelo. Barcelona: Ariel, 2004, p. 155); «Vida de la Asociación. Fundamento de los Círculos de Estudios», Boletín de la ACNdP, 1, 15-V-1924; "En Castilla avanza el regionalismo. Nombramiento de una comisión ejecutiva en Ávila. Conferencia del señor Gil-Robles", El Debate, 4-XII-1923.

46. "El parlamentarismo y la R.P. Conferencia del señor Gil-Robles en el Partido Social Popular», $E l$ Debate, 11-I-1924. 
DEL PRIMER JOSÉ MARÍA GIL-ROBLES (1898-1931)

del poder público, unas matizadas críticas que, en todo caso, no pusieron en cuestión la estrategia colaboracionista del propagandismo ${ }^{47}$.

De hecho, Gil-Robles prestó su ayuda al Directorio en materias técnicas, notablemente en lo relativo a la reforma municipal. Reclamado por José Calvo Sotelo, director general de Administración durante el Directorio Militar, cooperó en la redacción del nuevo Estatuto Municipal y de su posterior reglamento; concretamente redactó los artículos sobre legislación electoral, que contemplaban la elección popular del alcalde en un marco corporativo, que introducían fórmulas proporcionales y que posibilitaban un matizado sufragio femenino, del que se excluía a las mujeres sujetas a patria potestad, autoridad marital o tutela (en esencia, las casadas) ${ }^{48}$.

El Estatuto Municipal, extenso y complejo —sumaba más de 600 artículos_, reforzaba en esencia la autonomía municipal y la autoridad del alcalde, en la idea de despolitizar la vida local. Un artículo de El Debate, sin firma pero indudablemente redactado por Gil-Robles, definía la norma como la "más honradamente revolucionaria» que habría conocido España, "en tal vez siglos», cuyo único talón de Aquiles podría ser que los ciudadanos no la entendieran si no se divulgaba convenientemente ${ }^{49}$. La sugerencia no cayó en saco roto, de modo que Calvo Sotelo organizó la conocida como "campaña municipalista», en esencia una serie de mítines por teatros de toda España, siendo Gil-Robles uno de los más activos oradores de dicha campaña. De palabra o por escrito, el salmantino sostuvo que el municipio, entendido como «sociedad natural» prepolítica, era "un hecho de convivencia social natural, anterior y superior al Estado» y que, por eso mismo, su plena autonomía era salvaguardia de la verdadera libertad. Señaló al centralismo decimonónico como principal enemigo y animó a los asistentes a organizarse en grupos de intereses para participar en la vida local50.

Las mayores objeciones procedieron de auditorios católicos femeninos, ya que la ley negaba el voto a las mujeres casadas; Teresa Luzzatti, dirigente de la Acción Católica

47. "Formas prácticas de actuación política», Boletín de la ACNdP, 4, 1-V-1925. Sobre Unión Patriótica, GonzÁlez CAlleja, Eduardo: La España de Primo de Rivera. La modernización autoritaria, 1923-1930. Madrid: Alianza Editorial, 2005, pp. 164-200; Gómez-NAVArro, José Luis: «Unión Patriótica: análisis de un partido del poder, Estudios de Historia Social, 32-33, 1985, pp. 93-163.

48. En abril de 1924 Calvo Sotelo acudió al Primer Congreso Internacional de Ciudades, celebrado en París, con la intención de dar a conocer el Estatuto municipal recién aprobado. Junto a Gil-Robles redactó un folleto sobre autonomía municipal editado en francés, aunque la idea se malogró porque el texto en cuestión estaba "plagado de erratas» (cfr. Bullón de MendozA, Alfonso: op. cit., pp. 130-139).

49. "La nueva ley municipal», El Debate, 9-III-1924; «Dificultades superables», El Debate, 11-III-1924.

50. Gil-Robles, José María: "Asociaciones y municipios”, Diario de Valencia, 21-V-1924. Tales fueron sus críticas al Estado centralista en un mitin de Bilbao, que la prensa liberal de aquella capital tachó a Gil-Robles de "entusiasta enemigo de la libertad, de la democracia y del sufragiom. Evidentemente Gil-Robles, formado en el tradicionalismo, no interpretaba ninguno de aquellos conceptos en clave de democracia liberal (cfr. "Gil-Robles. No hemos entendido bien", La Noche (Bilbao), 17-III-1924; De Zuazagoitia, Joaquín: "Ni músicas ni alegatos; canciones», La Noche (Bilbao), 8-IV-1924).

(C) Ediciones Universidad de Salamanca / CC BY-NC-ND

Stud. hist., H. ${ }^{a}$ cont. 38 , 2020, pp. 267-295 
de la Mujer, avisó de los efectos perversos de dicha exclusión, que involuntariamente quizá, daba "preponderancia a las uniones ilegítimas» sobre los matrimonios canónicos. Gil-Robles se descolgó en su primer mitin con la peregrina idea de que «se ha quitado el voto a la mujer casada porque podía proporcionar disgustos a la familia", pero fue capaz de modular su opinión al constatar el malestar de las católicas. Admitió así que votar de cuando en cuando no privaría a la mujer de sus «efluvios espirituales» y que incluso el sufragio femenino favorecía la causa católica (porque las mujeres "Son menos viciosas» y actúan "como encantadoras de la voluntad de los hombres»), pero dejó claro que una cosa era votar y otra muy distinta el querer gobernar la cosa pública, función para la que la mujer estaba de momento incapacitada ${ }^{51}$.

No hubo oportunidad de comprobar las consecuencias del voto femenino, porque la Dictadura nunca convocó comicios municipales. En cualquier caso, Gil-Robles salió inquieto de su experiencia en la campaña municipalista, con mítines repletos de autoridades y fuerzas vivas de siempre, y "escasa conmoción" entre los hombres nuevos que se reclamaban como activos de la regeneración política. A la altura de octubre de 1924, Gil-Robles aún confiaba en la implicación municipal de industriales, comerciantes, gerentes y hombres de negocios, más inclinados a resolver problemas concretos que a teorizar ${ }^{52}$.

Se confirmaron esos temores y el Estatuto Municipal no llegó a estar plenamente en vigor. Sí fructificaron en cambio los congresos municipalistas, que nacieron del impulso conjunto del jurista Luis Jordana de Pozas, del alcalde de Madrid, Fernando Suárez de Tangil —conde de Vallellano—y del propio Gil-Robles. El primer congreso

51. "La conferencia del señor Calvo Sotelo en el Gran Teatro", La Voz. Diario gráfico de Información (Córdoba), 20-V-1924; "Unión Patriótica», El Defensor de Córdoba, 16-V-1924; "El acto feminista. La Infanta Isabel se ha inscrito en el censo electoral», La Correspondencia Militar, 1-VII-1924; "La Infanta doña Isabel inscrita en el censo", El Debate, 29-VI-1924. En un discurso posterior, de 1930, ante la Asamblea Nacional de la Milagrosa, Gil-Robles señaló que el feminismo «es uno de los grandes castigos de Dios sobre la sociedad contemporánea». Y matizó un poco su posición sobre la presencia de la mujer en la esfera pública: «Está bien que las mujeres acudan a la tribuna pública y funden sindicatos, pero sería preferible que no se olvidasen nunca del sindicato de sus hijos». En su caso, la mujer debía centrar su acción en «aquellas obras de carácter afectivo presidida por la caridad" (cfr. "Continúa la Asamblea de La Milagrosa. Conferencia del señor Gil-Robles sobre la familia”, El Debate, 1-V-1930. Una visión de conjunto, Blasco Herranz, Inmaculada: "Ciudadanía femenina y militancia católica en la España de los años veinte: el feminismo católico». En: Boyd, Carolyn P. (ed.): Religión y política en la España contemporánea. Madrid: Centro de Estudios Políticos y Constitucionales, 2007.

52. "La Liga Municipalista. Tercera reunión del Círculo de Estudios. Cuestiones municipalistas", en Boletín de la ACNdP, 3, 17-X-1924. Si Gil-Robles se había mostrado inquieto en los círculos de la ACNdP, en las páginas de El Debate aparentaba mayor triunfalismo, refiriendo discursos magistrales, teatros a rebosar, masas enfervorizadas y emancipadas de los caciques y una vieja política supuestamente a la fuga, porque "los nuevos núcleos ciudadanos surgen" (cfr. "Córdoba entusiasta y optimista. Otro éxito de la propaganda municipalista. Crónica telefónica de José María Gil-Robles», El Debate, 21-V-1924). 
DEL PRIMER JOSÉ MARÍA GIL-ROBLES (1898-1931)

tuvo lugar en Madrid en octubre de 1925, con el objeto de poner en marcha el Estatuto Municipal, lo que no se consiguió como se ha visto. Se puso énfasis en cuestiones de corte técnico, como el fomento de las mancomunidades, la formación de los funcionarios municipales o el impulso a los servicios locales. El evento se organizó deprisa y corriendo por las dudas del Directorio y apenas logró reunir a delegados de 85 municipios, una mínima parte de los más de nueve mil existentes entonces ${ }^{53}$. Enzarzados los congresistas en debates bizantinos, no hubo tiempo para plantear cuestiones que Gil-Robles consideraba esenciales, como la política de casas baratas o los límites del control de la Hacienda pública sobre las cuentas locales ${ }^{54}$.

Con tantos cabos sueltos, se acordó celebrar un segundo congreso poco después, en abril de 1926, en cuya organización Gil-Robles estuvo nuevamente implicado. Con mayor éxito que el primero, se adhirieron unos setecientos municipios, en su mayoría ciudades grandes y medianas, con escasísima presencia de lo que Jordana llamó «el proletariado corporativo local». Al menos se dio forma a la Unión de Municipios Españoles (UME), un órgano permanente de coordinación que se asoció a la Union International des Villes et Pouvoirs Locaux. La ejecutiva de la UME tuvo quince miembros, con Vallellano como presidente y Gil-Robles como tesorero ${ }^{55}$.

Las obligaciones del salmantino en la UME debieron de ser muy intensas en aquellos meses, pues apenas consta incluso su asistencia a los círculos de la ACNdP. En octubre de 1926 formó parte de la delegación española en el Congreso Internacional de Ciudades, celebrado en Düsseldorf ${ }^{56}$. Allí los españoles se apuntaron un tanto al obtener la organización del Congreso de 1929 para Sevilla, coincidiendo con la proyectada Exposición Iberoamericana, éxito que no sirvió de mucho a su promotor, el conde de Vallellano, forzado a dimitir de la alcaldía de Madrid en abril de 1927 tras sus desencuentros con el Directorio. Con Vallellano fuera, Gil-Robles dio por acabada su etapa en la UME y redujo notablemente su actividad municipalista; solo consta su presencia en la Semana Municipal de Oviedo en 1927, donde, casualidad o no, pronunció un discurso inusualmente crítico con el Directorio, al entender que éste se precipitaba anunciando la creación de una Asamblea Nacional sin haber culminado la ardua tarea

53. "Congreso Nacional Municipalista”, La Época, 15-X-1925; «El Congreso Municipalista. Designación de comisiones dictaminadoras", El Imparcial, 16-X-1925; "Congreso Municipalista. Solemne sesión de clausura", El Debate, 26-X-1925.

54. "Sesión del 29 de octubre», Boletín de la ACNdP, 12, 5-XI-1925.

55. «El Congreso Municipalista. En la sesión de hoy han quedado nombrados el Consejo directivo y el Comité permanente», Heraldo de Madrid, 1-V-1926; JoRdana DE Pozas, Luis: "El segundo Congreso Municipalista", El Debate, 2-V-1926

56. VV.AA.: Doctrina de los congresos municipalistas, 1926-1929. Madrid: Publicaciones de la Unión de Municipios Españoles, 1992; Orduña Rebollo, Enrique: «La Unión de Municipios Españoles: Antecedentes y evolución del municipalismo asociativo", Revista de Estudios de la Administración Local y Autonómica, 300-301, 2006, pp. 335-354. 
de "reconstruir los municipios». Aunque se dijo conforme con la base corporativa de aquella Asamblea, Gil-Robles no dejó de señalar que en el proyecto del Directorio "Sobran algunas representaciones y faltan otras" $\$ 7$.

Sobre el grado de colaboración entre Gil-Robles y la Dictadura hay no poco escrito. El interesado siempre la negó, o al menos la matizó, limitándola a una simple participación técnica en aquellos asuntos que mejor podía conocer. Uno de sus biógrafos, Juan Arrabal, afirmó en 1933 que el por entonces jefe de la CEDA era «enemigo de las dictaduras, vengan de donde vinieren" y que si se entusiasmó con el pronunciamiento de Primo de Rivera fue por «un anhelo de democracia» que muy pronto se desbarató. «Vio venir la marejada y la dejó pasar», apostillaba el amable biógrafo. Pero ni Gil-Robles se decepcionó de inmediato ni su colaboración fue meramente testimonial. Arrabal situó la supuesta ruptura de Gil-Robles con la Dictadura en una fecha tan temprana como septiembre de 1924, cuando supuestamente mostró su contrariedad por el modo de construir UP por parte del Directorio ${ }^{58}$. Pero dicho discurso, que tampoco se produjo en los términos descritos por Arrabal, no supuso ni mucho menos una ruptura ${ }^{59}$. No tuvo reparo en asistir al titulado como «homenaje de la Unión Patriótica al Directorio y al Gobierno", celebrado en Madrid en diciembre de 1925, al calor de Alhucemas. Lejos de ver en el Directorio un peligro, por esas mismas fechas defendió en un círculo de la ACNdP que el momento político era una magnífica oportunidad para que los derechistas conquistaran las cátedras universitarias, que él creía monopolizadas por la Institución Libre de Enseñanza ${ }^{60}$.

El nombre de Gil-Robles llegó incluso a sonar como Director general de Enseñanza Superior del ministro Callejo, asegurando algún medio que dicho nombramiento era inminente ${ }^{61}$. Pero la elección no cristalizó, parece ser que porque al dictador no le convencía el perfil del salmantino, quien en repetidas ocasiones se había declarado enemigo del Estado docente, al entender que la enseñanza era, ante todo, cosa de los padres $^{62}$. Otras versiones señalan que Gil-Robles quería el cargo a toda costa y que

57. «La Semana Municipal. Bajo la presidencia del señor Gobernador civil se celebra la sesión de clausura", La Voz de Asturias, 27-IX-1927.

58. Arrabal, Juan: op. cit., pp. 81-83.

59. En un clima de plena sintonía con el dictador, Gil-Robles señaló en Soria que UP estaba llamada a ser una "verdadera cruzada de apostolado ciudadano» (cfr. "Mitin de Unión Patriótica en Soria", El Avisador Numantino, 1-X-1924).

60. "El homenaje de la Unión Patriótica al Directorio y al Gobierno», La Nación, 11-XII-1925: "La Unión Patriótica Montañesa”, La Voz, 12-VII-1927; "Tercera imposición de insignias en Madrid. El banquete», Boletín de la ACNdP, 15, 20-XII-1925.

61. "Nombramientos", El Pueblo (Valencia), 23-XII-1925; "De madrugada. La Dirección de Enseñanza", La Prensa (Tenerife), 24-XII-1925.

62. Sobre Gil-Robles y la educación, cfr. "Círculo de estudios", El Debate, 1-I-1923; "Acto de afirmación escolar", Las Provincias. Diario de Valencia, 12-III-1927. 
DEL PRIMER JOSÉ MARÍA GIL-ROBLES (1898-1931)

para conseguir su propósito «no dejaba a sol ni a sombra al dictador», quien finalmente contentó al pedigüeño nombrándole juez municipal en Madrid ${ }^{63}$. Es lícito pensar, con estos mimbres, que si Gil-Robles no colaboró en mayor medida con la Dictadura no fue por su oposición a la deriva que ésta tomó —algo solo evidente en 1929—, sino porque Primo y los suyos no le requirieron.

Aparte de la política, Gil-Robles convirtió su bufete en uno de los más influyentes de la capital de España, asumiendo muchos pleitos en defensa de intereses locales frente al Estado y a vecinos particulares: recuperación de bienes comunales, disputas por la titularidad de fincas, demandas de segregación municipal o cobros indebidos de impuestos fueron los encargos más habituales, que Gil-Robles litigó aprovechando su envidiable posición en el asociacionismo católico ${ }^{64}$. Sirva de ejemplo lo ocurrido en Sigüenza, donde Gil-Robles, tras un acto de afirmación municipalista, asistió junto al obispo a "consultas interesantísimas de representantes de varios ayuntamientos sobre patrimonio municipal ${ }^{65}$. Para el prestigioso abogado, su especialización en defensa de los municipios era un correlato de su profunda creencia en la plena autonomía local ${ }^{66}$. El nombre de Gil-Robles se asoció también a pujantes grupos de interés, como la Comisión del Motor y del Automóvil, de la que fue miembro, o a la Agrupación de Empresas Cinematográficas, para la que actuó como letrado. Consta además la frecuente presencia de Gil-Robles en audiencias ministeriales, acompañando a asociaciones de intereses vinculadas al campo o a la empresa, para las que actuaba como conseguidor en asuntos como la construcción de embalses y canales de riego, o la compra y permuta de fincas en beneficio de los sindicatos agrarios católicos ${ }^{67}$.

Sin desligarse de estos negocios, Gil-Robles siguió colaborando en la promoción de las Juventudes Católicas. En mayo de 1927 se incorporó a la Junta Central de Acción Católica, como vocal en las comisiones de Acción Social y de Cultura, Enseñanza y

63. No nos parece una versión muy creíble porque, aunque Gil-Robles sí fue juez municipal, solo comenzó a ejercer como tal en 1928, casi tres años después de los rumores que le vincularon a la Dirección General de Enseñanza Superior (cfr. "De juez municipal a definidor de la República", La Tierra, 3-V-1934).

64. "Del Ayuntamiento. Créditos a favor de Ciudad Rodrigo", Miróbriga. Semanario Católico, 1-III-1925; "Anoche en el concejo. Primera reunión de un pleno extraordinario", El Adelanto. Diario de Salamanca, 6-I-1926; "De Montes", La Palanca. Semanario independiente (Guadalajara), 20-I-1926; "Intereses provinciales. Villar de Plasencia y sus problemas más interesantes", Nuevo Diario. Diario de la provincia de Cáceres, 9-VI-1928.

65. "Afirmación municipalista y agraria", Flores y abejas. Periódico literario y de noticias (Guadalajara), $11-\mathrm{I}-1925$.

66. «Se celebró ayer la vista del recurso contencioso-administrativo interpuesto por los de Moreda contra su junta vecinal», La Voz de Asturias, 14-X-1928; "Vista del recurso contencioso sobre la segregación de Moreda del Ayuntamiento de Aller», Región (Oviedo), 14-X-1928.

67. "Protección a la industria nacional. La Comisión del Motor y del Automóvil», La Época, 11-IV-1927; "Tres querellas de la Agrupación de Empresas Cinematográficas», La Voz, 12-VII-1927. Algunos ejemplos de las visitas ministeriales de Gil-Robles: "En Hacienda”, El Sol, 17-III-1927; "El conde Guadalhorce», La Vanguardia, 24-VIII-1927; "En Instrucción Pública», La Nación, 7-XI-1929; "En Economía», La Época, 28-VII-1930. 
Educación, lo que unido a sus tareas en El Debate le convirtieron en una de las figuras más reconocibles del activismo católico ${ }^{68}$. Con todo, sus mayores empeños en la etapa final de la Dictadura fueron en el seno de la influyente Confederación Nacional Católico-Agraria (CNCA), que sumaba por entonces cuatro mil sindicatos agrícolas locales y unas 600 mil familias asociadas, fundamentalmente en Castilla y León ${ }^{69}$. Gil-Robles asumió la secretaría general en un momento en el que la Dictadura trataba de implantar el orden corporativo en las relaciones sociolaborales, lo que para el propagandismo constituía una buena oportunidad para afianzar su liderazgo sobre el asociacionismo católico en su conjunto. Pero el corporativismo agrario no salió adelante, entre otros motivos por los recelos de la propia CNCA, que no acababa de congeniar con las pulsiones intervencionistas del régimen y que temía ser desplazada por los socialistas en los futuros comités paritarios del campo, como había ocurrido en la industria. Pese a todo, la CNCA fue una plataforma más en el reconocimiento público de Gil-Robles en los ambientes católicos; supo negociar con éxito la adquisición de varios latifundios para su distribución entre colonos asociados y tramitó créditos agrarios en favor de campesinos pobres a través de las cajas rurales, de reconocida filiación católica ${ }^{70}$.

Aunque las organizaciones católicas de las que formó parte Gil-Robles (ACNdP, CNCA...) eran formalmente apolíticas, Feliciano Montero ha señalado «su estrecha connivencia con los ideales y valores nacionalcatólicos de la Dictadura de Primo y su tendencia natural a colaborar con el régimen ${ }^{71}$. Sirva de colofón el que Gil-Robles utilizara el marco del I Congreso de la Juventud Católica Española, en 1927, para elogiar al Directorio por su promoción del «concepto cristiano de la organización de clases ${ }^{72}$. Si los propagandistas estaban disgustados con el régimen, no lo evidenciaron hasta casi el final.

\section{EN DEFENSA DE LA MONARQUÍA}

Los círculos de la ACNdP fueron un laboratorio de ideas para el conjunto del asociacionismo católico. En ellos se debatió sobre materias tan variadas como la monarquía, el corporativismo, el fascismo, el regionalismo o la legitimidad del poder, analizando los

68. "La Junta Central de Acción Católica», El Siglo Futuro, 14-V-1927.

69. Castillo, Juan José: Propietarios muy pobres. Sobre la subordinación política del pequeño campesino en España (La Confederación Nacional Católico-Agraria, 1917-1942). Madrid: Ministerio de Agricultura, 1979.

70. Gil-Robles, José María: «El aspecto fundamental del crédito agrícola. Una función esencial», El Día de Palencia, 7-VIII-1930; "La benemérita labor de los sindicatos católicos agrícolas», El Día de Palencia, 7-XI1929; Polo Benito, José: "Por el campo y la ciudad. La Asamblea Nacional de Acción Católica", El Defensor de Córdoba, 20-XI-1930; "Parcelación de una finca en Valoria de Alcor», El Siglo Futuro, 7-XI-1930.

71. Montero, Feliciano: op. cit., pp. 160-162.

72. "El Congreso Nacional de la Juventud Católica», El Siglo Futuro, 14-II-1927. 
DEL PRIMER JOSÉ MARÍA GIL-ROBLES (1898-1931)

grandes marcos teóricos y sus aplicaciones prácticas para el caso español. Gil-Robles, muchas veces ausente antes de 1928-1929, se convirtió tras esa fecha en uno de los principales dinamizadores de los círculos, siendo sus intervenciones una fuente de primera mano para conocer su pensamiento en aquellos años.

A pocos meses de proclamarse la República, seguía siendo deudor de la tradición paterna. Rebatía, por ejemplo, la separación entre Iglesia y Estado, defendiendo la primacía de lo religioso, porque Jesucristo era «soberano en lo temporal» y no exclusivamente de lo espiritual. Esa soberanía de Cristo obligaba al Estado a «mantener la libertad de la Iglesia" y a ésta a ejercer poder indirecto sobre lo temporal, "como un consejo o como un mandato", según los $\operatorname{casos}^{73}$. A propósito de la dictadura como forma de gobierno, argumentó que podía ser legítima si se ejercía en beneficio de la nación y no derivaba en despótica. Bajo su punto de vista los gobiernos de Mendizábal, Espartero, Narváez o González Bravo fueron dictaduras ilegítimas, porque se erigieron en favor de un partido y carecieron de nervio renovador y patriótico ${ }^{74}$. Gil-Robles no mencionó a Primo de Rivera, aunque puede colegirse que supeditaba su legitimidad al mantenimiento de su pulso reformista y a su capacidad de seguir aunando voluntades, dos condiciones problemáticas en el momento de dictar su lección, a finales de 1928.

Cuando en 1930 se trató de democracia, Gil-Robles se reafirmó en sus consabidos prejuicios contra el liberalismo. Menos entusiasmo mostró aún por la soberanía nacional, que calificó como una utopía solo posible con una ciudadanía suficientemente instruida, de la que España carecía por completo. Sí admitía, a la luz de León XIII, la obligación del pueblo católico de no permanecer pasivo ante una democracia de ese tipo, con mayor razón su la religión estuviera en peligro. No hará falta recordar cuál fue la actitud del grueso del propagandismo a raíz del 14 de abril de 1931. La democracia ideal, en todo caso, sería la democracia cristiana, que Gil-Robles entiende como sinónimo de democracia corporativa, sustentada, por este orden, en municipios, en organizaciones sociales y solo en última instancia, en agrupaciones políticas ${ }^{75}$. Tampoco en esto se advierte una evolución sustancial en el pensamiento de Gil-Robles entre 1920 y 1931. Y sin embargo, una parte del mundo carlista ya levantó contra él las primeras sospechas de traición, por liberalizante, como se verá a continuación.

Una de las causas del postrero divorcio entre la dictadura y los propagandistas fue el modelo de corporativismo implantado por Primo en la Organización Corporativa Nacional, que para Herrera suponía un triunfo del tipo sindicalista fascista dado el fuerte intervencionismo estatal que, a su juicio, la normativa contemplaba. Con algo más que frialdad se recibió en la ACNdP la excesiva presencia socialista en los comités

73. "Madrid. La Semana del Estudiante», Boletín de la ACNdP, 48, 20-II-1928.

74. "La dictadura en España en el siglo XX", El Imparcial, 17-XI-1928.

75. "Estudio sobre la democracia", Boletín de la ACNdP, 101, 5-XII-1930; "La resistencia al poder", Boletín de la ACNdP, 82, 20-XII-1929. 
paritarios, una crítica coincidente con la de la de patronos y Sindicatos Libres ${ }^{76}$. En todo caso, Herrera pidió a los suyos que evitaran «toda oposición sistemática o violenta a la política social del Gobierno", en la esperanza de que Primo rectificara ${ }^{77}$.

A pesar de esta recomendación, Gil-Robles se convertiría en el primer propagandista relevante en desmarcarse públicamente de la dictadura, en agosto de 1929. Durante un viaje por Estados Unidos firmó un largo artículo de opinión en El Debate, con el sugestivo título de «Reformar o aprovechar?». El escrito era una refutación del proyecto de Estatuto Fundamental de la dictadura, tachado de casuístico y detallista, equiparable a las constituciones democráticas en su manía de «querer echar a tierra lo existente», ignorando las tradiciones. Lo sorprendente era que Gil-Robles, el carlista de cuna que coqueteó con la derecha radical en 1923, se transfiguraba en defensor de la Constitución canovista, de la que pedía su vuelta en vigor con las necesarias reformas obligadas por el tiempo ${ }^{78}$. Solo seis años antes había denunciado «el absoluto divorcio entre la constitución real de la nación española y la Constitución de 1876»79. ¿Significa eso que Gil-Robles se había vuelto canovista? En absoluto, pero Gil-Robles entendía que invocar a Cánovas en aquellos momentos era el mejor remedio para poner freno al peligro totalizante que representaba el Estatuto Fundamental. La constitución filoinglesa de Cánovas volvía a ser para Gil-Robles el mal menor, pero si en 1920, cuando redactó su tesis doctoral, lo era frente a la democracia liberal, nueve años después lo era frente a las tentaciones fascistas de la dictadura.

Esta supuesta pirueta de Gil-Robles fue jaleada por La Época, periódico conservador por excelencia, con la misma intensidad que El Siglo Futuro la condenó. Un durísimo editorial del diario tradicionalista, "El padre y el hijo», contraponía el talento de Enrique Gil y Robles, «martillo de hierro que pulverizaba la doctrina y la política de los católicos afines a la obra de Cánovas», con el carácter volátil de su hijo, fiel exponente de lo que el diario definía como "la escuela de El Debate ${ }^{80}$. En realidad, lo que El Siglo Futuro buscaba era ajustar cuentas con el carlista tránsfuga, sin reparar que Gil-Robles se servía de Cánovas para salvar las tradiciones amenazadas por lo que interpretaba como el ataque totalizador de un Estado voraz, asumiendo que la táctica podía ser

76. "Madrid. El Círculo comienza el estudio de régimen de organización corporativa", Boletín de la $A C N d P, \mathrm{~N}^{\circ} 75,20-\mathrm{V}-1929$; «Vida de los centros. Madrid. El Círculo de estudios ha continuado ocupándose del régimen de organización corporativa", Boletín de la $A C N d P$, 76, 5-VI-1929. Una visión de conjunto, GoNZÁLEz CAlleja, Eduardo: op. cit., pp. 153-164.

77. "La Asamblea de Loyola", Boletín de la ACNdP, 78, 5-VII-1929.

78. Gil-Robles, José María: “Reformar o aprovechar?», El Debate, 26-VIII-1929; "El Sr. Gil-Robles, en la Casa del Estudiante», $A B C, 27-$ III-1930.

79. "En Castilla avanza el regionalismo. Conferencia del señor Gil-Robles», El Debate, 4-XII-1923.

80. "La reforma constitucional. En defensa del Código de 1876», La Época, 26-VIII-1929; ANDRADE, Benito M.: «Democracia conservadora», La Época, 3-IX-1929; ClarovER: «El padre y el hijo», El Siglo Futuro, 27-VII-1929. 
DEL PRIMER JOSÉ MARÍA GIL-ROBLES (1898-1931)

más perentoria que la ideología. Para el carlismo representado por El Siglo Futuro, en cambio, combinar mal menor y defensa de la tradición era un puro contrasentido.

Habiendo dimitido Primo de Rivera, los círculos de la ACNdP focalizaron sus trabajos en la defensa de la monarquía. Se debatió sobre el principio de autoridad, sobre la resistencia al poder e incluso, sobre la oportunidad de fundar un nuevo partido de corte católico y agrario. Ante la posibilidad de insurreccionar contra un poder constituido, los propagandistas estudiaron las posiciones contrapuestas de Balmes y de León XIII, siendo Gil-Robles el encargado de glosar al Pontífice. El primero justificaba la rebelión en determinados casos ("que los que pretenden derribar al gobierno estén seguros de su ilegitimidad, que se propongan sustituirle por un poder legítimo" y "que cuenten con probabilidad de buen éxito»); el segundo la condenaba siempre, porque su consumación podía ocasionar un mal mayor que el que trataba de evitarse; en su caso, cabía combatir las leyes injustas "por todos los medios legales y honrados", o en circunstancias extremas, con la "no obediencia" ${ }^{81}$.

En el momento de plantearse el debate —finales de 1929- no era previsible la proclamación de una República, por lo que la masiva adhesión al grupo a las tesis de León XIII debería entenderse como una defensa de la monarquía en apuros. Convendría recordar que Gil-Robles, adalid de León XIII en 1930, se apoyó en Balmes en circunstancias bien distintas en $1937^{82}$.

La ACNdP advirtió también que mantener la monarquía en aquellos momentos exigía acciones más contundentes de cara a la opinión pública. En marzo de 1930 el círculo de Madrid aprobó la organización de mítines por toda España en unión de otros políticos de derechas, cuyo equívoco nombre, "campaña de orientación social», pretendía en realidad «despertar en las gentes el deseo de actuar ciudadanamente» en defensa de ideales como Religión, Monarquía, Orden, Autoridad, Familia, Enseñanza, Propiedad y Reformas sociales. Uno de los más entusiastas con la iniciativa sería Gil-Robles, que auguró un gran éxito de convocatoria al interpretar — sin demasiado tino- que «la gente de la derecha» estaba muy movilizada ${ }^{83}$.

El mitin inaugural de la campaña tuvo lugar el 13 de abril de 1930 en el Teatro de la Comedia de Madrid, con discursos de Severino Aznar, Pío Zabala, José María Valiente y José María Gil-Robles, en presencia de conocidas personalidades monárquicas y católicas. La idea era que cada orador saliera en defensa de un principio esencial

81. "El Círculo de Estudios de Madrid. Comienza el año 22 de sus trabajos», Boletín de la ACNdP, 80, 20-XI-1929; "La resistencia al poder», Boletín de la ACNdP, 82, 20-XII-1929.

82. "Una carta de Gil-Robles en The Universe", El Día de Palencia, 18-II-1937.

83. "Campañas del momento. Los propagandistas y la política", Boletín de la ACNdP, 87, 5-III-1930. GilRobles imputó a Ángel Herrera el fracaso de la campaña, por su general «desorientación». Gil-Robles eludió toda responsabilidad, lo que no sorprende, porque evitar la autocrítica sería característico de su liderazgo (cfr. Gil-Robles, José María: op. cit., p. 97). 
de la buena política. Gil-Robles, que glosó el Orden, relacionó este concepto con el catolicismo social, fustigando a los ricos por amenazar el orden social con su egoísmo y su corrupción, frases que, a pesar de su contundencia retórica, no debieron causar gran impresión en su auditorio, habituado a escucharlas en los sermones de las misas dominicales. Los mayores aplausos los cosechó con la parte más derechista del discurso, al proclamar que «el orden hay que guardarlo, cueste lo que cueste» y que, si eso no fuera posible, "tiene que surgir necesariamente la mano atrevida, el golpe audaz" ${ }^{84}$.

Días después, en Santiago de Compostela, un caldeadísimo mitin monárquico fue interrumpido por las protestas de estudiantes afines a la Federación Universitaria Escolar. Gil-Robles, que hablaba en presencia del arzobispo, del alcalde, del rector y del comandante militar, replicó enojado que los enemigos del Rey lo eran también de la patria, aunque el incidente no fue a más y el mitin no se suspendió. El orador concluyó advirtiendo que derrocar la monarquía «sería el atraso de España y de las demás instituciones y detendría el progreso de España "85. Sin embargo, la división de los monárquicos fue más poderosa que los voluntariosos intentos de unidad. La indecisión de Alfonso XIII y la inanidad del gobierno Aznar en nada les ayudaba. En medio de la confusión, Gil-Robles publicó un artículo en prensa advirtiendo que la Constitución solo podía ser reformada por voluntad conjunta de Rey y Cortes y que, por eso mismo, una convocatoria unilateral de Constituyentes por parte del Rey equivaldría «a un golpe de Estado dado por el monarca» 86 .

La movilización monárquica en la que El Debate cifraba sus mayores esperanzas fue la liderada por las ligas agrarias de las provincias castellano-leonesas, capaces por sí solas de convocar grandes audiencias, pero lastradas por la falta de líderes y de programas y por su mal disimulada continuidad con la disuelta UP. Aun así, el diario de Ángel Herrera advertía que ningún futuro partido de derechas podría tener éxito sin la fuerza del agrarismo. «Háblase ya de candidatos para las próximas elecciones del partido agrario, siendo nosotros quienes deben nombrarlos», clamó un tal José Castrillo ante una masa de labradores en Zamora ${ }^{87}$, frase nada anecdótica si se considera que

84. «Se inaugura brillantemente la campaña de Orientación Social», El Debate, 15-IV-1930; «Movimiento social. Campaña de orientación social», La Lectura Dominical, 19-IV-1930

85. "Importante acto en Santiago", El Debate, 22-IV-1930; "Sesión 28 del Círculo de Estudios", Boletín de la ACNdP, 93, 5-VI-1930. Gil-Robles se mostró particularmente activo a la hora de denunciar a las organizaciones intelectuales y universitarias de perfil progresista, como la mencionada FUE o el Ateneo de Madrid. Fue uno de los firmantes de una instancia dirigida a Berenguer exigiendo el fin de las subvenciones públicas al Ateneo, al haberse convertido, en opinión de los peticionarios, en «asilo de enemigos del régimen existente en España" (cfr. "Contra un acuerdo antipatriótico. Adhesiones a una instancia», ABC, 29-XI-1930).

86. Gil-Robles, José María: «La reforma constitucional», El Bien Público. Diario monárquico (Mahón), 14-I-1931.

87. "Ante el movimiento agrario", El Debate, 12-X-1930; "Asamblea de la Unión Agraria en Zamora", El Debate, 14-X-1930, «Un posible candidato», El Imparcial, 10-I-1931. 
DEL PRIMER JOSÉ MARÍA GIL-ROBLES (1898-1931)

Gil-Robles saldría elegido diputado por Salamanca en las Constituyentes de 1931 en el seno de una candidatura agraria —el Bloque Agrario—, que aparentemente seleccionó a sus candidatos por aclamación popular.

La agraria no fue la única opción posible para Gil-Robles; señala Bullón de Mendoza que estuvo a punto de integrarse en la recién constituida Unión Monárquica Nacional, por invitación expresa de su líder, el conde de Guadalhorce. Aunque el salmantino se mostró dispuesto a colaborar, al final renunció a hacerlo al advertir que el nuevo partido no era otra cosa que restos del naufragio del primorriverismo. Se justificó argumentando que «adherirse al núcleo de los exministros equivaldrá a suscribir toda la obra de la dictadura, en la cual hay ciertamente mucho de bueno, pero también no poco malo». Además, el proyecto le pareció artificioso, sobrado de personalismos y falto de contenido doctrinal; la derecha, subrayaba, solo podía reconstruirse con hombres nuevos ${ }^{88}$.

Aunque no se integrara en la UMN, Gil-Robles coincidió con alguno de sus líderes en una nueva y atropellada campaña monárquica con motivo de la convocatoria a elecciones municipales para el 12 de abril de 1931. Esta campaña, conocida como Reacción Ciudadana, contó con la participación de Gil-Robles en plazas aparentemente sencillas para la causa, como Segovia, Ávila, Santander, Torrelavega o Béjar. Entre duques, marqueses y condes, Gil-Robles se declaró en Segovia abiertamente monárquico «en virtud de un hondo y antiguo convencimiento». Identificó la monarquía con valores como continuidad, unidad o estabilidad y redujo el republicanismo a un sarampión pasajero. Subiendo el tono, en Ávila definió a los republicanos como «fracasados de todos los partidos" y "vividores despechados" 89 .

El 12 de abril pasó lo que pasó y si hubiera que fiarse de las memorias de GilRobles - lo que a veces constituye un acto de fe-, el orador desafiante y fervoroso encerraba en la intimidad un monárquico inseguro y preocupado por la poca movilización de los suyos, cuyos temores se verían confirmados en el recuento electoral; en su mesa de la madrileña calle Guzmán el Bueno, un barrio de rentas medias-altas, la Conjunción republicano-socialista batió a los monárquicos en proporción de tres a uno $^{90}$. Solo tres días después, El Debate, del que era subdirector, proclamaba la legitimidad de la nueva República e invitaba a los católicos a acatarla en un comentadísimo editorial, "Ante un poder constituido».

88. Bullón de Mendoza, Alfonso: op. cit., p. 251.

89. "La reacción ciudadana. Importante acto público en Segovia», ABC. 24-III-1931; "Brillante mitin en Segovia de Reacción Ciudadana», El Debate, 24-III-1931; "En el Teatro Principal de Ávila», La Nación, 10-IV-1931; "La propaganda electoral», El Cantábrico, 7-IV-1931; "El mitin monárquico de anoche en Béjar», El Adelanto. Diario de Salamanca, 12-IV-1931. Una visión de conjunto, en Ben-Ami, Shlomo: Los orígenes de la Segunda República española: anatomía de una transición. Madrid: Alianza Editorial, 1990, pp. $310-323$.

90. Gil-Robles, José María: No fue posible la paz. Barcelona: Ariel, 1968, pp. 32-33. 
Nadie esperaba la República tan pronto, aunque los propagandistas no habían descartado su posible proclamación a más largo plazo. El mismo Gil-Robles había glosado meses antes en la ACNdP la doctrina de León XIII, según la cual, «el cambio de forma en los gobiernos no extingue el deber de obedecerlos". Ante un auditorio de "Luises» había incidido en este pensamiento al admitir que «la ilegitimidad de origen no puede, por sí sola, justificar la no sumisión al poder» ${ }^{11}$. Y si el mal se producía, los católicos alemanes ya habían mostrado el camino tiempo atrás creando el Zentrum, un partido capaz de vencer el desafío del Kulturkampf sin renunciar a la legalidad ${ }^{22}$. En muy pocos meses, Gil-Robles y los suyos tendrían ocasión de aplicar esta receta en España.

\section{A MODO DE CONCLUSIÓN}

La etapa de juventud de Gil-Robles aporta claves sugerentes de su carácter, capacidad de liderazgo y modo de entender la acción política. En sus últimos años universitarios desarrolló una marcada personalidad, avalada por una fuerte confianza en sí mismo y en sus potencialidades. A ello se unía una reconocida capacidad de trabajo, solo ensombrecida por su tendencia a la dispersión: abogado, periodista, activista católico, viajero, mitinero, catedrático ocasional..., el Gil-Robles de 1931 estaba fabricado bastante antes del 14 de abril.

Aunque supo evolucionar y adaptar su discurso a las circunstancias, el Gil-Robles político poseía certezas inmutables: inamovible fe religiosa, escasa confianza en la democracia parlamentaria, defensa del corporativismo católico, rechazo al excesivo intervencionismo del Estado, necesidad de conquistar a la opinión y a las masas. Jamás renunció a un cierto sustrato tradicionalista, razón de su no adhesión al pujante fascismo, del que sin embargo admiró sus modernas propagandas para movilizar a las masas. Lo escrito confirmaría, en palabras de Pilar Salomón, la existencia de «solapamientos y entrecruzamientos» entre las distintas culturas políticas que conformaron la derecha católica española del primer tercio del siglo $\mathrm{XX}^{93}$.

La cuestión de la monarquía fue el terreno en el que el Gil-Robles de 1931 más se distanció del Gil-Robles de 1920, aunque en el seno del propagandismo ya se había planteado el carácter accesorio de las formas de gobierno. Gil-Robles, como Luis Lucia,

91. "La resistencia al poder", Boletín de la $A C N d P$, 82, 20-XII-1929; "La sumisión al poder constituido", Unión Monárquica, 107, 1-IV-1931.

92. "Brillantísimo acto de fin de curso del Círculo de Estudios de Madrid", Boletín de la ACNdP, 94, 20-VI-1930.

93. Salomón, Pilar: op. cit., pp. 315-317; GonzÁlez Cuevas, Pedro Carlos: "Tradicionalismo, catolicismo y nacionalismo durante el régimen de la Restauración (1898-1930)", Ayer, 71, 2008, pp. 25-52. 
fue un perfecto ejemplo de la acomodación — que no aceptación - de los católicos políticos al mundo democrático-liberal, capaz de sacrificar el trono para defender la tiara.

¿Mostró Gil-Robles madera de líder antes de 1931? Ambicioso y triunfador, crecido con pocos contratiempos - salvo por la muerte de su padre y por su escaso apego a la disciplina militar-, maduró junto a sus acomodados compañeros de la ACNdP, con los que compartía el sueño de una España no liberal armonizada por el catolicismo: era y se sentía élite. No obstante, un liderazgo sólido también requiere otras virtudes, como la estabilidad emocional, la templanza o fajarse ante las adversidades, virtudes que, según coinciden correligionarios y adversarios, Gil-Robles nunca tuvo ${ }^{94}$. La prueba de fuego, en cualquier caso, habría de llegarle en el seno de un régimen muy distante de sus principios doctrinales: una República democrática y parlamentaria.

94. González Calleja, Eduardo; Rodríguez lópez-Brea, Carlos: «José María Gil-Robles, el caudillo devenido en villano». En: Mees, Ludger (ed.): Héroes y villanos de la patria. Madrid: Tecnos (en prensa). 